\title{
Energy Use and Carbon Emissions Efficiency Study of Chinese Regions Based on Price Factor
}

\author{
Yuansheng Huang, Yan Zhang* \\ Department of Economics and Management, North China Electric Power University, Baoding, P.R. China
}

Received: 14 July 2017

Accepted: 1 October 2017

\begin{abstract}
As China has committed to the international community to effectively control $\mathrm{CO}_{2}$ emissions, it is necessary for the regions of China to launch an in-depth analysis about energy use and $\mathrm{CO}_{2}$ emission efficiency. In this paper, each province of China will be regarded as an independent decision-making unit. After judging their return to scale state by the traditional DEA theoretical model, we use the SBM and $\mathrm{RE} / \mathrm{CE}$ models, which respectively solve the problems of slack variables, and the traditional model does not reflect factors such as price, which is truly existing. Then we get a more comprehensive efficiency that reveals Chinese energy use and the $\mathrm{CO}_{2}$ emissions situation. From the empirical study of 30 regions in China, we know that the southern region of China has the most efficient score while northeastern China has poor performance. Price factor has a significant influence on energy use and $\mathrm{CO}_{2}$ emissions efficient score of some provinces. Our study shows that northern and northeastern China should make more of an effort on energy consumption reduction in order to improve the efficiency score. Instead, northeastern and central China should pay more attention improving energy conversion technology in order to increase their efficiency.
\end{abstract}

Keywords: green gas emission, energy use efficiency, data envelopment analysis, energy price

\section{Introduction}

A large amount of energy consumption and sharp growth of greenhouse gases, which result in global warming, has become a key problem globally [1]. It has been proved that greenhouse gas emissions are responsible for sea level rise and the increase in the frequency of droughts. In this respect, the signing of the Kyoto Protocol to control atmospheric greenhouse gas concentrations worldwide and the Copenhagen Accord

*e-mail: hsezzhangyan@163.com that followed it, on the basis of objective evidence, states the necessity for significantly decreasing greenhouse gas emissions worldwide.

Due to increased warnings of environmental pollution and technical innovation to reduce the emissions of greenhouse gas, greenhouse gases of developed countries are in decline while in developed countries they have grown at high-speed [2]. China, as the largest carbon emission country in the world, will certainly face great responsibility in reasonably reducing and controlling carbon emissions and the greenhouse effect [3-6]. Therefore, it is important for energy waste and the greenhouse effect to take the 
necessary treatment. In the $13^{\text {th }}$ Five-Year Plan the Chinese government has formulated more specific energy program development goals. Achieving the above objectives is highly correlated in order to reduce $\mathrm{CO}_{2}$ emissions and improve energy efficiency [7]. Beyond that, China has committed to reducing its carbon emissions by $40-45 \%$ per unit of GDP by 2020 compared with 2005. The heart of the matter is how to decompose the total goal for each province in an effective and reasonable way and to improve efficiency with a huge difference like development level and energy structure between these provinces [8-9]. We also should adopt a more efficient way to optimize resource utilization and improve the environment. It can help the regional governments or the relevant departments to improve energy configuration efficiency and rectify the condition of energy use, and timely adjust energy management principles, put forward a more effective low-carbon program, and put it into action.

Data envelopment analysis (DEA) has been a relatively non-parametric approach widely used in solving the problem of energy allocation. Charnes et al. [10] used DEA to evaluate the energy efficiency of many decision-making units (DMUs). DEA can also obtain a better result without prior functional form and assumptions [11]. Zhou et al. [12] used a non-radial DEA method based on entropy weight and SBM model to directly address the evaluation of environmental efficiency of the power industry in order to make it more reliable and reasonable. For the problem of economic determinants of energy efficiency in the European iron and steel industry, Florens Fluesa [13] investigated the factors of market and policy related to the decreased specific energy consumption, and found out that the increased energy prices lead to higher energy efficiency. Yuan Peng [14] established an input-output method that can be used to measure carbon emissions growth to be four factors of carbon emissions intensity, technology, domestic final demand, and trade. Sheng et al. [15] presented a non-parametric input distance function for estimating the shadow price to described energy utilization. The results obtained from these provinces at lower energy utilization can by improved upon in order to reallocate inputs.

DEA has been accepted as an effective tool for evaluating energy efficiency in many studies, but few studies for analysis of carbon emissions use this technique. Cao Ming et al. [16] proved that the SBM model that considered undesirable outputs can better evaluate energy efficiency and the development of industrial low carbon. Wang et al. [17] presented a nonradial directional distance function method for the problem of carbon emissions efficiency and reduction cost who indicated that provincial carbon emission efficiencies are different because of provincial economic development. Yang et al. [18] examined the impact of carbon emissions on provincial economic convergence by using the environmental total factor productivity. In addition, the results showed that GDP and carbon emissions had a great deal of influence on provincial economic convergence.

In the above-mentioned traditional energy efficiency analysis model, the author typically treats energy efficiency as a direct result of DUM technological level and energy demand, ignoring the effect of energy price. In fact energy price has a significant impact on making the energy program of the region government. Market energy price and energy technology result in the existing energy use and the level of carbon emissions. As a result of this deletion, existing research has commonly overlooked economic factors for the efficiency of energy use, making the existing energy efficiency research results fail in reacting more comprehensively and accurately to the situation.

This paper decomposes $\mathrm{CO}_{2}$ emissions growth from energy consumption in China into 3 categories of factors: technology efficiency, domestic final demand, and price. Considering that the energy price was influenced by global energy scenario and government macro-control, each DUM had to change already market price effects, therefore each DUM has to contend with and obey price factor. The aim of the present paper is to evaluate carbon efficiency with price factor. Compared with traditional functions, the distance function model with price factor improved model accuracy. Matching real production status with the more reliable method of formulating the optimal allocation schemes of energy use on the macro-level provides a reliable base for regional governments to improve energy efficiency.

\section{Material and Methods}

\section{Return to Scale}

In this section, we first judge return to scale (RTS) of DMUs by measuring the energy use and $\mathrm{CO}_{2}$ emission efficiency for each province in CCR and BCC models. Then we present a slack-based measurement model to provide us with more accurate efficiency and to capture excess slack movement of inputs and outputs. Lastly, considering economic variables such as price of inputs and outputs, a modified model is given to allocate the waste gas emissions and energy-effective reductions among the province based on cost of inputs and revenue of outputs.

Suppose there are $n$ decision-making unites (DMU) denoted by DMUj $(j=1,2, \ldots, n)$. Every DMU includes $m$ different kinds of inputs and q different kinds of outputs. Define $\mathrm{Xj}=(\mathrm{X} 1 \mathrm{j}, \mathrm{X} 2 \mathrm{j}, \ldots, \mathrm{Xmj}) \mathrm{T}$, and $\mathrm{Yr}=(\mathrm{Y} 1 \mathrm{j}, \mathrm{Y} 2 \mathrm{j}, \ldots$ ,Yqj) as the input and the output vectors of DMUj. Where $\theta$ is scalar, the value obtained is the efficiency value of the DMUj.

Data envelopment analysis model with constant scale pay (CCR): 


$$
\begin{gathered}
\theta^{*}=\min -\varepsilon\left(\sum_{i=1}^{m} q_{i}^{-}+\sum_{r=1}^{s} q_{r}^{+}\right) \\
\text {s.t. }=\left\{\begin{array}{c}
\sum_{\mathrm{j}=1}^{n} \lambda_{j} x_{i j}+q_{i}^{-}=\theta_{x_{i o}}, i=1, \cdots, m \\
\sum_{\mathrm{j}=1}^{n} \lambda_{j} y_{r j}+q_{i}^{+}=y_{r o}, r=1, \cdots, q \\
\lambda_{j} \geq 0, j=1,2, \cdots, n
\end{array}\right.
\end{gathered}
$$

Solving the linear programming problem, let $\theta^{*}$ be the optimal value, if $\theta^{*}$ is 1 , and the slack variable $\mathrm{q}_{\mathrm{i}}^{+}=\mathrm{q}_{\mathrm{r}} ;(\mathrm{i}=1,2 \ldots \mathrm{m} ; \mathrm{r}=1,2 \ldots \mathrm{q})$, then the DMU is valid for DEA if the relaxation variable is not all 0 . It is valid for weak DEA, otherwise DEA is invalid.

Data envelopment analysis model with variable scale pay (BCC):

$$
\begin{gathered}
\theta^{*}=\min -\varepsilon\left(\sum_{i=1}^{m} q_{i}^{-}+\sum_{r=1}^{s} q_{r}^{+}\right) \\
\text {s.t. }=\left\{\begin{array}{c}
\sum_{\mathrm{j}=1}^{n} \lambda_{j} x_{i j}+q_{i}^{-}=\theta_{x_{i o}}, i=1, \cdots, m \\
\sum_{j=1}^{n} \lambda_{j} y_{r j}+q_{i}^{+}=y_{r o}, r=1, \cdots, q \\
\lambda_{j} \geq 0, j=1,2, \cdots, n \\
\sum_{\mathrm{j}=1}^{n} \lambda_{j}=1
\end{array}\right.
\end{gathered}
$$

As we know, there are undesirable outputs like $\mathrm{SO}_{2}, \mathrm{NO}_{\mathrm{X}}$, and $\mathrm{CO}_{2}$ emissions, and the correct handling of undesirable outputs leads to better efficiency of numerical value measurement and a more accurate efficiency score. There are mainly three ways to process data about undesirable outputs. The first is treating the undesirable outputs as fictitious inputs [19-20]. The second is changing the form of the undesirable outputs [21], which is what we have chosen for this paper. The third way is adding a fictitious inverse on undesirable outputs and enough large positive vector [22-24].

By applying the CCR and BCC models [25], we get technical efficiency (TE, the efficiency value CCR model find) and pure technical efficiency (PTE, the efficiency value $\mathrm{BCC}$ model find) of each province. The score of PTE is equal to or greater than the TE score, so the relationship can be used to measure scale efficiency (SE) [26-27]:

$$
\mathrm{SE}=\mathrm{TE} / \mathrm{PTE}
$$

We can also know the value of $\sum \lambda^{*}$, which refers to the sum of the weight coefficiency of Lambda. Known by the judgment method of RTS:
1) $\mathrm{SE}=1$ means the DMUj is in a state of scale reward and is constant (CRS).

2) $\mathrm{SE}<1$ and in the optimal solution $\sum \lambda^{*}<1$, means the DMUj is in a state of increasing return to scale (IRS).

3) $\mathrm{SE}<1$ and in optimal solutions $\sum \lambda^{*}>1$ means the DMUj is in a state of diminishing return to scale (DRS).

If we know the right RTS that each DMU belongs to, we can choose a corresponding model to get more accurate energy use and $\mathrm{CO}_{2}$ emission efficiency for each province.

\section{Slack-Based Measurement Model} (SBM)

This model was introduced by Tone (2001). Besides allowing us to measure the energy use and $\mathrm{CO}_{2}$ efficiency of different provinces, it can also calculate the excess slack movement of inputs and outputs. The slack movement expresses how far the current performance of the DMU in each variable is from its ideal performance [28].

$$
\begin{gathered}
\min \rho=\frac{1-\frac{1}{m} \sum_{i=1}^{m} \frac{s_{i}^{-}}{x_{i k}}}{1+\frac{1}{q} \sum_{r=1}^{q} \frac{s_{r}^{+}}{y_{r k}}} \\
\text { s.t. } X \lambda+s^{-}=x_{k} \\
Y \lambda-s^{+}=y_{k} \\
e \lambda \leq 1 \\
\lambda, s^{-}, s^{+} \geq 0
\end{gathered}
$$

In model (2), $\rho$ is the efficiency score, which measures the inefficient situation from two aspects of input and output at the same time, so it's a non-oriented model. $e$ stands for a row vector in which all elements are 1 , as $e=(1,1, \ldots, 1) ; s^{+}, s^{-}$are slack movement. In the SBM model, we calculate the average efficient score by measuring degree of inefficiency of all input (output) that can be reduced (increased), which solved the problem that the radial model doesn't contain the measuring of inefficiency of slack movement.

\section{Distance Function Model with Price Factor}

DEA is widely used because its efficiency analysis doesn't need the price information of index. But when the price information is known, we can further use price information on the analysis of configuration efficiency [29-30].

In 2007 the ratio efficiency of income and cost (RE/CE) was proposed by Cooper William W, which extends the traditional cost efficiency (CE) and revenue efficiency (RE) models to a comprehensive model with input-output data, and their corresponding prices are known. 
If we know all prices of each index, we get a whole new model based on cost efficiency (CE) and revenue efficiency (RE) models, the ratio efficiency of income and cost $(\mathrm{RE} / \mathrm{CE})$.

$$
\begin{aligned}
& \frac{R E}{C E}=\frac{e \overline{y_{0}} / e \bar{y}^{*}}{e \bar{x}_{0} / e \bar{x}^{*}} \\
& \frac{e{ }^{*}}{{ }^{*}}=\max \frac{e \bar{y}}{-} \\
& \text { ex c } x \\
& \text { s.t. } \bar{x}=\bar{X} \lambda \leq \overline{x_{0}} \\
& \bar{y}=\bar{Y} \lambda \geq \bar{y}_{0} \\
& \lambda \geq 0
\end{aligned}
$$

$\bar{x}_{i, j}$ stands for the element of matrix $\bar{X}, x_{i, j}=c_{i, j} \times x_{i, j}$, $c_{i, j}$ is price of $x_{i, j}(i=1,2, \ldots, n) \cdot \bar{y}_{i, j}$ stands for the element of matrix $\bar{Y}, \bar{y}_{i, j}=r_{i, j} \times y_{i, j}, r_{i, j}$ is price of $y_{i, j}(i=1,2, \ldots, q)$, $(j=1,2, \ldots, n)$ and $(e=1,1, \ldots, 1)$ like Eq. (2).

Generally speaking, when we calculate efficiency we can't enumerate all relevant input and output elements, so the profit may be a negative number [31], which means when we know some, maybe not all, index variables and their prices, we can use the ratio efficiency of income and cost model to get a more comprehensive and accurate efficiency score.

\section{Variables and Date}

In this section, we select four kinds of variables: labor, energy consumption, value added, $\mathrm{SO}_{2}$ and $\mathrm{NO}_{\mathrm{X}}$, and $\mathrm{CO}_{2}$ emissions with the associated data. After this, we judge RTS of each DMU to choose a corresponding model. Then the SBM model under NIRS (no-increasing to scale) status is used to analyze the energy and $\mathrm{CO}_{2}$ emission efficient score for 30 provinces while obtaining the slack movements of each variable. Lastly we analyzed the influence of price on energy use and $\mathrm{CO}_{2}$ emission efficiency to each province by using the $\mathrm{RE} / \mathrm{CE}$ model.

In this section, we examine the efficient score of 30 provinces in China (with 2016 being the latest available date). As the number of DMUs should not be less than five times the number of index variable [32], the paper selects five variables as inputs and outputs. We employ (1) labor: the number of employed people of each province in the country and city as the non-energy inputs variable; (2) energy consumption includes coal, crude oil, and natural gas as energy inputs variable; (3) value-added of each province in 2016 as desirable outputs variable; (4) harmful gas emissions of $\mathrm{SO}_{2}$ and $\mathrm{NO}_{\mathrm{x}}$ is regarded as one kind of undesirable output variable, and the emission of $\mathrm{CO}_{2}$ as the main dioxide emission is regarded as another undesirable output variable. Measurement of variables is summarized in Table 1.
Table 1. Introduction of variables.

\begin{tabular}{|c|c|c|}
\hline Inputs/Outputs & Variable & Unit \\
\hline Non-energy inputs & Labor & $10^{4}$ persons \\
\hline Energy inputs & Energy & $\begin{array}{c}10^{4} \text { tons of coal equiva- } \\
\text { lent }(10,000 \text { tce })\end{array}$ \\
\hline Desirable outputs & Value added & $10^{8} \mathrm{RMB}$ \\
\hline $\begin{array}{c}\text { Undesirable } \\
\text { outputs }\end{array}$ & $\mathrm{SO}_{2}$ and $\mathrm{NO}_{\mathrm{x}}$ & $10^{4}$ tons \\
\cline { 2 - 2 } $\mathrm{CO}_{2}$ & \multicolumn{2}{|c}{} \\
\hline
\end{tabular}

Date shown in Table 2 is about inputs, value added and emission of $\mathrm{SO}_{2}$ and $\mathrm{NO}_{\mathrm{x}}$ collected from "The Provincial Statistical Yearbook" and "The Provincial Energy Statistical Yearbook."

As there are no $\mathrm{CO}_{2}$ emissions data in these yearbooks, we calculated the emission of $\mathrm{CO}_{2}$ using a model called fuel-based carbon footprint, which has been successfully used in some theses [33-35].

$$
\mathrm{CO}_{2} \text { emission }=\frac{44}{12} \sum_{i=1}^{n}\left(A_{i} \times C C F_{i} \times H E_{i} \times C O F_{i}\right)
$$

In this model, $\mathrm{Ai}$ is the consumption of different fuel, CCFi is the carbon content factor, $\mathrm{HE}$ is the heat equivalent, and COFi is the carbonaceous fuel. According to Eq. (4) and date in Tables 2-3, we can get the estimation value of $\mathrm{CO}_{2}$ shown in Table 2 .

Before applying the model to measure the efficient score of each province, we should process the date of undesirable outputs. Assuming that a DMUj undesirable outputs primitive value is $\mathrm{Cj}$, conversion equation is $\mathrm{Cj}^{*}=\operatorname{maxCj}+\operatorname{minCj}-\mathrm{Cj}$ (which not only achieves the purpose of avoiding output value of 0 , but also guarantees the transformation with the original values in the same magnitude, laying a foundation for the introduction of price factor).

At the Subsection 3.4 we will use the RE/CE model, but we should know the price of all variables. The price can be divided into two categories: the price of the inputs variable and the price of the outputs variable.

\section{The Price of Inputs Variable}

We can get the price of different provinces in primary, secondary, and tertiary industries about labor and energy from the "Provincial Statistical Yearbook." Treating the proportion of labor and energy consumption in different industries as weight, we calculated the average of labor and energy price. Then we get the average price of inputs variable (Table 4).

\section{The Price of Outputs Variable}

1) Value added: As valued added treats "yuan" as its unit, we make the price of value added as one yuan/yuan. 
Table 2. Raw date of 30 provinces (energy: 104 tons of coal equivalent; labor: 104 persons; value added: $108 \mathrm{RMB} \mathrm{SO}_{2}, \mathrm{NO}_{\mathrm{X}}, \mathrm{and} \mathrm{CO}_{2}$ : 104 tons).

\begin{tabular}{|c|c|c|c|c|c|c|c|}
\hline \multirow{2}{*}{ DMU } & \multirow{2}{*}{$\begin{array}{c}\text { Energy inputs } \\
\text { Energy }\end{array}$} & \multirow{2}{*}{$\begin{array}{c}\begin{array}{c}\text { Non-energy } \\
\text { inputs }\end{array} \\
\text { Labor } \\
\end{array}$} & \multirow{2}{*}{$\begin{array}{c}\begin{array}{c}\text { Desirable } \\
\text { outputs }\end{array} \\
\text { Value added }\end{array}$} & \multicolumn{2}{|c|}{$\begin{array}{l}\text { Undesirable outputs } \\
\text { (unprocessed) }\end{array}$} & \multicolumn{2}{|c|}{$\begin{array}{l}\text { Undesirable outputs } \\
\text { (processed) }\end{array}$} \\
\hline & & & & $\mathrm{SO}_{2} \& \mathrm{NO}_{\mathrm{x}}$ & $\mathrm{CO}_{2}$ & $\mathrm{SO}_{2} \& \mathrm{NO}_{\mathrm{x}}$ & $\mathrm{CO}_{2}$ \\
\hline Beijing & $21,330.83$ & $4,230.68$ & 755.86 & 22.99 & $8,856.28$ & 308.13 & $92,732.70$ \\
\hline Tianjin & $15,726.93$ & $6,480.97$ & 299.96 & 49.15 & $15,068.33$ & 281.96 & $86,520.66$ \\
\hline Hebei & $29,421.15$ & $21,900.30$ & 656.16 & 270.24 & $53,330.82$ & 60.87 & $48,258.17$ \\
\hline Shanxi & $12,761.49$ & $28,584.46$ & 455.40 & 227.81 & $70,167.80$ & 103.30 & $31,421.18$ \\
\hline Inner Mongolia & $17,770.19$ & $27,226.90$ & 258.80 & 257.07 & $66,968.81$ & 74.04 & $34,620.18$ \\
\hline Liaoning & $28,626.58$ & $22,674.75$ & 658.94 & 189.66 & $53,690.24$ & 141.46 & $47,898.75$ \\
\hline Jilin & $13,803.14$ & $9,138.65$ & 300.22 & 92.15 & $22,122.71$ & 238.96 & $79,466.28$ \\
\hline Heilongjiang & $15,039.38$ & $13,243.19$ & 430.80 & 120.28 & $31,805.95$ & 210.83 & $69,783.04$ \\
\hline Shandong & $59,426.59$ & $40,400.82$ & $1,252.03$ & 318.35 & 97,03686 & 279.02 & $84,105.35$ \\
\hline Shanghai & $23,567.70$ & $7,661.80$ & 730.46 & 52.09 & $17,483.64$ & 117.38 & $39,777.42$ \\
\hline Jiangsu & $65,088.32$ & $25,927.06$ & $1,602.39$ & 213.73 & $61,811.56$ & 204.93 & $66,592.51$ \\
\hline Zhejiang & $40,173.03$ & $14,794.89$ & $1,126.32$ & 126.19 & $34,996.48$ & 201.08 & $70,425.01$ \\
\hline Anhui & $20,848.75$ & $12,804.61$ & 521.78 & 130.03 & $31,163.98$ & 254.35 & $79,357.22$ \\
\hline Fujian & $24,055.76$ & $9,445.22$ & 650.85 & 76.76 & $22,231.77$ & 223.66 & $86,502.06$ \\
\hline Jiangxi & $15,714.63$ & $6,199.22$ & 453.55 & 107.45 & $15,086.92$ & 12.76 & $4,552.12$ \\
\hline Henan & $34,938.24$ & $19,527.58$ & $1,081.19$ & 262.02 & $47,355.40$ & 69.09 & $54,233.59$ \\
\hline Hubei & $27,379.22$ & $10,865.81$ & 768.80 & 116.40 & $26,116.33$ & 214.71 & $75,472.66$ \\
\hline Hunan & $27,037.32$ & $9,242.55$ & 582.57 & 117.65 & $22,428.88$ & 213.47 & $79,160.11$ \\
\hline Guangdong & $67,809.85$ & $20,264.13$ & $1,962.65$ & 185.23 & $47,693.66$ & 145.89 & $53,895.33$ \\
\hline Guangxi & $15,672.89$ & $6,946.77$ & 394.48 & 90.90 & $16,725.24$ & 240.21 & $84,863.75$ \\
\hline Hainan & $3,500.72$ & $2,676.21$ & 63.28 & 12.76 & $5,823.28$ & 318.35 & $95,765.70$ \\
\hline Chongqing & $14,262.60$ & $6,446.10$ & 954.34 & 88.20 & $14,835.67$ & 242.92 & $86,753.32$ \\
\hline Sichuan & $28,536.66$ & $11,276.89$ & 748.08 & 138.18 & $25,847.37$ & 192.93 & $75,741.62$ \\
\hline Guizhou & $9,266.39$ & $10,485.06$ & 239.89 & 141.69 & $25,703.53$ & 189.43 & $75,885.45$ \\
\hline Yunnan & $12,814.59$ & $6,257.31$ & 285.10 & 113.56 & $15,486.19$ & 217.56 & $86,102.80$ \\
\hline Shaanxi & $17,689.94$ & $17,313.21$ & 500.62 & 148.67 & $41,439.32$ & 182.44 & $60,149.67$ \\
\hline Gansu & $6,836.82$ & $7,227.55$ & 237.72 & 99.40 & $17,198.38$ & 231.71 & $84,390.61$ \\
\hline Qinghai & $2,303.32$ & $2,041.64$ & 42.18 & 28.88 & $4,552.12$ & 302.23 & $97,036.86$ \\
\hline Ningxia & $2,752.10$ & $7,173.05$ & 111.33 & 78.11 & $17,472.22$ & 253.00 & $84,116.77$ \\
\hline Xinjiang & $9,273.46$ & $17,597.71$ & 87.49 & 171.58 & $40,879.62$ & 159.53 & $60,709.37$ \\
\hline
\end{tabular}

2) $\mathrm{SO}_{2}$ and $\mathrm{NO}_{\mathrm{x}}$ : Chinese file "Standard of Pollutant Discharge Fee and Calculation method" points out the fee of pollutant discharged based on the type and quantity of the pollution. Each pollution equivalent's imposition standard is 0.6 yuan. The calculation method of pollution equivalent is shown in Eq. (5). File specifies $\mathrm{SO}_{2}$ and $\mathrm{NO}_{\mathrm{X}}$ pollution equivalent value is
$0.95 \mathrm{~kg}$, so we know: price of $\mathrm{SO}_{2}$ and $\mathrm{NO}_{\mathrm{x}}$ emissions $($ emission tax $)=6.3158 * 106$ yuan/104 ton.

Pollution equivalent $=\frac{\text { emissions of pollutants }(\mathrm{kg})}{\text { pollution equivalent density }(\mathrm{kg})}$ 
Table 3. $\mathrm{CO}_{2}$ emission factors in China (standard coal efficiency: $\mathrm{kgce} / \mathrm{kg}$; CCF: tons carbon/trillion Joules; HE: trillion Joules/10 ${ }^{4}$ tons; $\mathrm{COF}: \%$ ).

\begin{tabular}{|c|c|c|c|}
\hline Fuel & Coal & $\begin{array}{c}\text { Crude } \\
\text { oil }\end{array}$ & $\begin{array}{c}\text { Natural } \\
\text { gas }\end{array}$ \\
\hline $\begin{array}{c}\text { Standard coal efficiency } \\
\text { (kgce/kg) }\end{array}$ & 0.7143 & 1.4286 & 1.3300 \\
\hline $\begin{array}{c}\text { CCF (tons carbon/trillion } \\
\text { Joules) }\end{array}$ & 27.28 & 20.1 & 15.32 \\
\hline HE (trillion Joules/10 $10^{4}$ tons) & 192.14 & 448 & 0.384 \\
\hline COF $(\%)$ & 92.3 & 98 & 99 \\
\hline
\end{tabular}

3) $\mathrm{CO}_{2}$ emission: The ministry of finance proposes that the Chinese carbon tax should depend on the consumption of coal, natural gas, and petroleum. Carbon tax paying started in 2012 at 10 yuan per ton of $\mathrm{CO}_{2}$ emissions; by 2020 , carbon tax can be increased to 40 yuan/ton. Assuming growth rate is constant, the price of $\mathrm{CO}_{2}$ emissions in 2016 is:

$$
\begin{gathered}
{\left[10 \times\left(\frac{40}{10}\right)^{\frac{2016-2012}{2020-2012}}\right] \text { yuan } / \text { ton }=14.14 \text { yuan } / \text { ton }} \\
=1.414 \times 10^{5} \text { yuan } / 10^{4} \text { ton }
\end{gathered}
$$

Now we know the price of all output variables.

\section{Results and Discussion}

\section{Judgment and Analysis of RTS}

We get all element of RTS judgment by using CCR and BCC models, then we figure out the result which is shown in Table 5. According to Table 5, we can find that all DMUs meet conditions (1) or (3) mentioned in Subsection 2.1, so the DMUs are all in a no increasing return to scale (NIRS) state.

\section{Efficient Score in SBM Model}

We apply the SBM model provided in Subsection 2.2 with the data in Table 2 to calculate energy use and $\mathrm{CO}_{2}$ emission efficient scores of 30 provinces. Considering that not all DMUs have slack movement, we only show the DMUs whose efficient scores are not 1 in Table 6.

According to Table 6, we can know that: (1) There are 10 provinces whose energy use and $\mathrm{CO}_{2}$ emission efficient score are all equal to 1: Beijing, Tianjin, Inner Mongolia, Shandong, Jiangsu, Hunan, Guangdong, Hainan, Qinghai, and Xinjiang. (2) Energy use and $\mathrm{CO}_{2}$ emission efficient scores for Hebei, Shanxi, Henan, and Ningxia are below 0.4 - especially Shanxi, whose efficient score was only 0.1643. (3) We can see from Table 6, for efficiency improvement, that low energy consumption and $\mathrm{CO}_{2}$ emissions have considerable space to improve. (5) Provinces like Hainan and Qinghai are not developed provinces, but their efficiency scores are all equal to one. Provinces like Shanxi and Liaoning

Table 4. Price of input variables.

\begin{tabular}{|c|c|c|c|c|c|}
\hline \multirow{2}{*}{ DMU } & \multicolumn{2}{|c|}{ Input price } & \multicolumn{2}{c|}{ Input price } \\
\cline { 2 - 3 } \cline { 5 - 6 } & $\begin{array}{c}\text { Labor } \\
(1 \mathrm{RMB} / \text { per person })\end{array}$ & $\begin{array}{c}\text { Energy } \\
(1 \mathrm{RMB} / \text { ton })\end{array}$ & & $\begin{array}{c}\text { Labor } \\
\text { DMU }\end{array}$ & $\begin{array}{c}\text { Energy } \\
(1 \mathrm{RMB} / \text { ton })\end{array}$ \\
\hline Beijing & $30,195.00$ & $1,871.99$ & Henan & $14,650.66$ & 920.36 \\
\hline Tianjin & $23,208.28$ & $1,336.73$ & Hubei & $15,454.72$ & $1,171.33$ \\
\hline Hebei & $14,522.47$ & 854.14 & Hunan & $13,912.10$ & $1,044.46$ \\
\hline Shanxi & $16,162.40$ & 420.86 & Guangdong & $25,233.87$ & $1,518.37$ \\
\hline Inner Mongolia & $17,060.59$ & 713.25 & Guangxi & $15,376.98$ & $1,368.31$ \\
\hline Liaoning & $15,472.22$ & $1,497.44$ & Hainan & $14,357.27$ & $1,929.08$ \\
\hline Jilin & $13,953.30$ & $1,083.98$ & Chongqing & $16,179.08$ & $1,192.64$ \\
\hline Heilongjiang & $11,173.92$ & $1,275.10$ & Sichuan & $14,941.17$ & $1,048.14$ \\
\hline Shandong & $21,541.75$ & $1,224.63$ & Guizhou & $13,586.23$ & 924.98 \\
\hline Shanghai & $33,075.58$ & $1,591.57$ & Yunnan & $15,014.08$ & 710.83 \\
\hline Jiangsu & $21,833.94$ & $1,126.73$ & Shaanxi & $16,378.55$ & 991.18 \\
\hline Zhejiang & $24,444.72$ & $1,266.08$ & Gansu & $13,120.98$ & $1,111.70$ \\
\hline Anhui & $15,433.22$ & $1,004.27$ & Qinghai & $13,927.05$ & 945.63 \\
\hline Fujian & $21,330.41$ & $1,299.80$ & Ningxia & $15,117.56$ & 4962.53 \\
\hline Jiangxi & $14,649.78$ & $1,013.22$ & Xinjiang & $15,408.19$ & 888.70 \\
\hline
\end{tabular}


Table 5. Elements of RTS judgment.

\begin{tabular}{|c|c|c|c|c|c|}
\hline DMU & SE & $\sum \lambda^{*}$ in CCR & DMU & SE & $\sum \lambda^{*}$ in CCR \\
\hline Beijing & 1 & 1 & Henan & 0.8973 & 2.0138 \\
\hline Tianjin & 1 & 1 & Hubei & 0.9255 & 1.1444 \\
\hline Hebei & 0.8911 & 2.2564 & Hunan & 1 & 1 \\
\hline Shanxi & 0.9276 & 1.4284 & Guangdong & 0.9441 & 2.8673 \\
\hline Inner Mongolia & 0.8874 & 1.7288 & Guangxi & 0.9175 & 1.0542 \\
\hline Liaoning & 0.8907 & 2.2462 & Hainan & 1.0000 & 1 \\
\hline Jilin & 0.9707 & 1.0426 & Chongqing & 0.6092 & 1.2193 \\
\hline Heilongjiang & 0.9302 & 1.2509 & Sichuan & 0.9184 & 1.1573 \\
\hline Shandong & 0.8535 & 4.3985 & Guizhou & 0.9224 & 1.0897 \\
\hline Shanghai & 0.9125 & 1.1064 & Yunnan & 0.9312 & 1.0406 \\
\hline Jiangsu & 0.8690 & 2.6901 & Shaanxi & 0.9201 & 1.5131 \\
\hline Zhejiang & 0.9126 & 1.6767 & Gansu & 0.6810 & 1.1962 \\
\hline Anhui & 0.9176 & 1.5497 & Qinghai & 1.0000 & 1 \\
\hline Fujian & 0.9121 & 1.1187 & Ningxia & 0.5509 & 1.2696 \\
\hline Jiangxi & 0.9259 & 1.0494 & Xinjiang & 1.0000 & 1 \\
\hline
\end{tabular}

Table 6. Efficiency score and slack movement in SBM model (energy: 104 tons of coal equivalent; labor: 104 persons; value added: 108 $\mathrm{RMB} ; \mathrm{SO}_{2}, \mathrm{NO}_{\mathrm{X}}$, and $\mathrm{CO}_{2}: 104$ tons).

\begin{tabular}{|c|c|c|c|c|c|}
\hline \multirow{2}{*}{ DMU } & \multirow{2}{*}{ Efficiency score } & \multicolumn{4}{|c|}{ Slack movement } \\
\hline & & Labor & Energy & $\mathrm{SO}_{2}$ and $\mathrm{NO}_{\mathrm{X}}$ & $\mathrm{CO}_{2}$ \\
\hline Hebei & 0.3631 & 0 & $11,843.86$ & 147.77 & $29,006.14$ \\
\hline Shanxi & 0.1643 & 212.85 & $23,026.32$ & 187.49 & $57,341.84$ \\
\hline Liaoning & 0.5066 & 22.57 & $13,002.59$ & 69.38 & $30,276.57$ \\
\hline Jilin & 0.6881 & 37.50 & $3,256.36$ & 48.73 & $8,509.09$ \\
\hline Heilongjiang & 0.4752 & 144.15 & $6,976.18$ & 73.18 & $17,257.52$ \\
\hline Shanghai & 0.8608 & 0 & $1,869.15$ & 1.89 & $4,471.84$ \\
\hline Zhejiang & 0.8563 & 0 & $2,940.00$ & 9.82 & $7,143.04$ \\
\hline Anhui & 0.6229 & 93.84 & $5,073.07$ & 49.86 & $12,762.48$ \\
\hline Fujian & 0.8376 & 0 & $2,566.21$ & 4.34 & $6,199.37$ \\
\hline Jiangxi & 0.7764 & 0 & $1,490.56$ & 77.31 & $4,654.54$ \\
\hline Henan & 0.3575 & 0 & $10,225.85$ & 187.41 & $26,147.04$ \\
\hline Hubei & 0.7782 & 0 & $3,184.36$ & 38.79 & $8,259.17$ \\
\hline Guangxi & 0.7927 & 95.56 & 482.62 & 41.91 & $1,697.77$ \\
\hline Chongqing & 0.4681 & 463.59 & $3,028.59$ & 63.02 & $7,578.27$ \\
\hline Sichuan & 0.7981 & 0 & $2,715.47$ & 44.73 & $5,632.42$ \\
\hline Guizhou & 0.4568 & 64.99 & $6,014.59$ & 111.77 & $15,520.45$ \\
\hline Yunnan & 0.7777 & 41.52 & 682.65 & 73.08 & $2,620.07$ \\
\hline Shaanxi & 0.4230 & 151.61 & $10,352.94$ & 87.63 & $25,093.51$ \\
\hline Gansu & 0.4583 & 108.48 & $3,686.63$ & 63.68 & $9,094.66$ \\
\hline Ningxia & 0.3419 & 60.53 & $4,983.00$ & 48.55 & $12,568.51$ \\
\hline
\end{tabular}


Table 7. The results of RE/CE model.

\begin{tabular}{|c|c|c|c|c|c|c|}
\hline \multirow{2}{*}{\multicolumn{2}{|c|}{ DMU }} & \multirow{3}{*}{$\begin{array}{c}\text { Efficiency score } \\
1\end{array}$} & \multicolumn{4}{|c|}{ Slack movement } \\
\hline & & & \multirow{2}{*}{$\frac{\text { Labor }}{0}$} & \multirow{2}{*}{$\begin{array}{c}\text { Energy } \\
0\end{array}$} & \multirow{2}{*}{$\frac{\mathrm{SO}_{2} \text { and } \mathrm{NO}_{\mathrm{X}}}{0}$} & \multirow{2}{*}{$\frac{\mathrm{CO}_{2}}{0}$} \\
\hline \multirow{6}{*}{ North } & Beijing & & & & & \\
\hline & Tianjin & 1 & 0 & 0 & 0 & 0 \\
\hline & Hebei & 0.7747 & 0 & $7,408.03$ & 138.88 & $25,775.98$ \\
\hline & Shanxi & 0.4320 & 212.73 & $17,484.13$ & 0 & $6,887.00$ \\
\hline & Inner Mongolia & 1 & 0 & 0 & 0 & 0 \\
\hline & average & 0.8413 & 42.55 & $4,978.43$ & 27.78 & $6,532.60$ \\
\hline \multirow{4}{*}{ Northeast } & Liaoning & 0.4455 & 62.54 & $15,682.52$ & 68.00 & $29,616.48$ \\
\hline & Jilin & 0.6741 & 0 & $4,234.01$ & 0 & $4,635.60$ \\
\hline & Heilongjiang & 0.4665 & 0 & $9,071.25$ & 0 & $11,680.66$ \\
\hline & average & 0.5287 & 20.85 & $9,662.59$ & 22.67 & $15,310.91$ \\
\hline \multirow{7}{*}{ East } & Shandong & 1 & 0 & 0 & 0 & 0 \\
\hline & Shanghai & 0.7601 & 158.37 & $2,183.59$ & 0 & $4,071.10$ \\
\hline & Jiangsu & 1 & 0 & 0 & 0 & 0 \\
\hline & Zhejiang & 0.8627 & 179.73 & $1,546.24$ & 0 & 0 \\
\hline & Anhui & 0.6553 & 27.08 & $3,749.73$ & 0 & $4,143.85$ \\
\hline & Fujian & 0.8612 & 12.65 & $2,579.76$ & 0 & $5,487.87$ \\
\hline & average & 0.8566 & 62.97 & $1,676.55$ & 0.00 & $2,283.80$ \\
\hline \multirow{5}{*}{ Central } & Jiangxi & 0.8288 & 116.67 & 0 & 23.50 & 0 \\
\hline & Henan & 0.8097 & 147.00 & $4,626.10$ & 124.42 & $16,749.09$ \\
\hline & Hubei & 0.7598 & 196.83 & $2,447.37$ & 0 & $3,535.29$ \\
\hline & Hunan & 1 & 0 & 0 & 0 & 0 \\
\hline & average & 0.8496 & 115.13 & $1,768.37$ & 36.98 & $5,071.10$ \\
\hline \multirow{4}{*}{ South } & Guangdong & 1 & 0 & 0 & 0 & 0 \\
\hline & Guangxi & 0.6789 & 26.43 & $1,776.02$ & 0 & 0 \\
\hline & Hainan & 1 & 0 & 0 & 0 & 0 \\
\hline & average & 0.8930 & 8.81 & 592.01 & 0.00 & 0.00 \\
\hline \multirow{5}{*}{ Southwest } & Chongqing & 0.4215 & 650.75 & $1,102.35$ & 8.25 & 0 \\
\hline & Sichuan & 0.8517 & 134.73 & $1,331.47$ & 16.71 & $1,866.68$ \\
\hline & Guizhou & 0.4958 & 0 & $6,650.86$ & 9.23 & 0 \\
\hline & Yunnan & 1 & 0 & 0 & 0 & 0 \\
\hline & average & 0.6923 & 196.37 & $2,271.17$ & 8.55 & 466.67 \\
\hline \multirow{6}{*}{ Northwest } & Shaanxi & 0.4585 & 77.70 & $8,989.32$ & 0 & $7,505.37$ \\
\hline & Gansu & 0.4362 & 0 & $3,993.11$ & 0 & $1,246.40$ \\
\hline & Qinghai & 1 & 0 & 0 & 0 & 0 \\
\hline & Ningxia & 0.4241 & 0 & $1,250.52$ & 3.90 & 0 \\
\hline & Xinjiang & 1 & 0 & 0 & 0 & 0 \\
\hline & average & 0.6638 & 15.54 & $2,846.59$ & 0.78 & $1,750.35$ \\
\hline
\end{tabular}




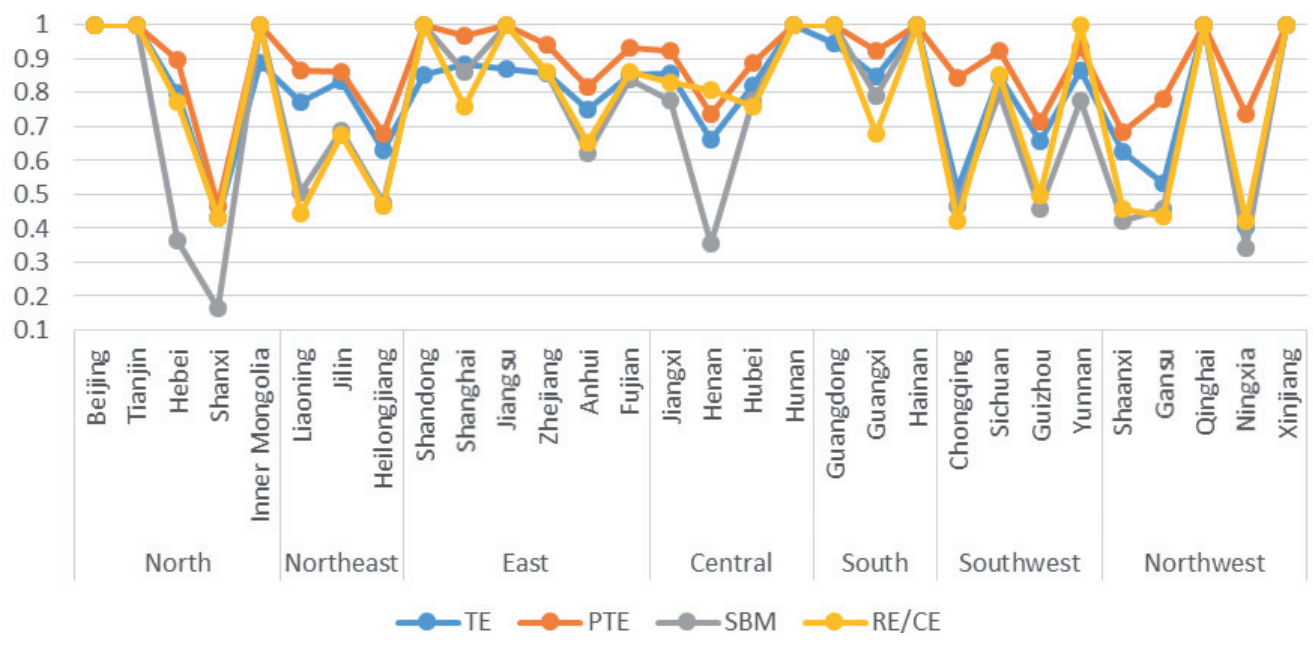

Fig. 1. Efficiency under the different models.

are more developed than Yunnan and Qinghai, while their performances are so poor, meaning that energy consumption and development level are not all factors that affect it. So we should use a new model that has the ability to consider more factors about energy use and $\mathrm{CO}_{2}$ emission efficiency.

\section{Efficient Score in RE/CE Model}

We measure the energy use and $\mathrm{CO}_{2}$ emission efficiency with a price factor of 30 provinces mentioned in Subsection 3.1. Then we got Table 7, including the results of efficiency score, inputs, and undesirable outputs reduction in the $\mathrm{RE} / \mathrm{CE}$ model.

From Table 7 we can see: (1) 11 provinces that performed very well, their energy use, and $\mathrm{CO}_{2}$ emission efficient scores are all equal to one. (2) 8 provinces' efficient scores are lower than 0.5. (3) The average of all DMUs efficient scores is higher than that in the SBM model, reflecting the energy use and that $\mathrm{CO}_{2}$ emission efficient scores of 30 provinces actually are at a higher level when we consider the truly existing price.

For better analysis in a bigger area, we group 30 provinces into 7 categories: north, northeast, east, central of China, south, southeast, northwest. Then we have the following conclusions. (1) Energy use and $\mathrm{CO}_{2}$ emission efficiency average of these areas are 0.8413 (northern China), 0.5287 (northeastern China), 0.8566 (eastern China), 0.8495 (central China), 0.8930 (southern China), 0.6923 (southeastern China), and 0.6638 (northwestern China), which indicates that southern China has the best performance. Northern, eastern, and central China have similar performance with efficiency scores all between 0.84 and 0.86 . Northeastern China has the worst performance among these areas. (2) In northern China, 3 out of 5 provinces are efficient, and Shanxi drives down the efficiency level of this area obviously. (3) Eastern and central China also performed

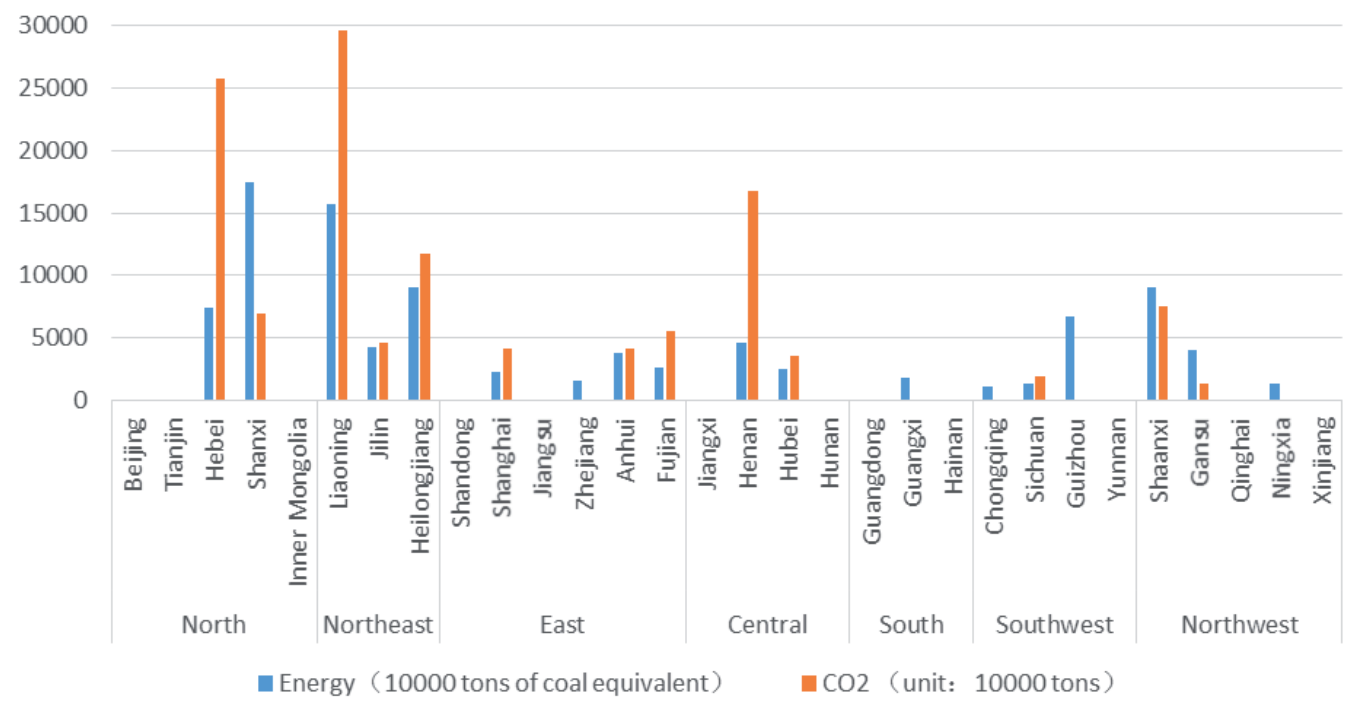

Fig. 2. Energy and $\mathrm{CO}_{2}$ emission reduction of seven areas. 
well on energy use and $\mathrm{CO}_{2}$ emission efficient score, and the efficiency of these provinces belonging to these two areas has no significant difference. (4) The northeastern area has the worst performance among these areas, with the highest score of this area being 0.6741 (Jilin).

For reflecting the impact of price factor on efficient score, we made Fig. 1: The efficiency under the different models and Fig. 2: Energy and $\mathrm{CO}_{2}$ emission reduction of seven areas. In Fig. 2 we only list the DMUs having slack movement.

From Fig. 1 we can find that: (1) Price factor has a significant influence on energy use and $\mathrm{CO}_{2}$ emission efficient score for some provinces, especially like Heibei, Shanxi, and Shanhai, etc. (2) Some province like Heibei, Shanxi, Henan, and Ningxia have efficiency scores higher than in the SBM model. Because these provinces have or are near rich energy sources, the price of energy and costs of energy transportation are low. When we consider the price factor, energy use and $\mathrm{CO}_{2}$ emission efficiency will be higher than before. (3) Some provinces like LiaoNing and Shanhai have efficiency scores all lower than before because the places like them are more developed, far from rich energy resources, and the price of energy and cost of energy transportation are high. When we use the model with price, the efficiency scores of these places will be lower.

According to Fig. 2: (1) Hebei, Shanxi, Liaoning, Heilongjiang, Henan, Guizhou, and Shaanxi have the heavier task of energy and $\mathrm{CO}_{2}$ emission reduction. (2) Beijing and Tianjin as the municipalities directly under the central government have great efficiency. But we should realize that this is more or less related to their location and political status. (3) The provinces with more energy reduction task and less $\mathrm{CO}_{2}$ emission reduction task like Shanxi and Shaanxi, should take more effort on energy consumption reduction to improve efficiency score. Instead, provinces like Hebei, Liaoning, and Yunnan with less energy reduction task and more $\mathrm{CO}_{2}$ emission reduction task should pay more attention to the improvement of energy conversion technology.

\section{Conclusions}

The energy shortage and a large amount of $\mathrm{CO}_{2}$ emissions have been a huge threat to the world, especially in developing countries such as China. As the largest energy consumer and $\mathrm{CO}_{2}$ emitter, China faces great responsibility of energy efficient use and reducing $\mathrm{CO}_{2}$ emissions, but it is unwise to evaluate energy use and $\mathrm{CO}_{2}$ emission efficiency without considering the price factor.

In this paper, we evaluate the energy use and $\mathrm{CO}_{2}$ emission efficiency of 30 provinces with price and allocate the reduction mission to each of them. In particular, after judging the RTS of 30 provinces, we first use the SBM model to provide more accurate efficiency. It is also able to capture excess slack movement of inputs and outputs of 30 provinces. Lastly, considering economic variables such as price of energy and $\mathrm{CO}_{2}$ emission, the $\mathrm{RE} / \mathrm{CE}$ model is given to allocate the waste gas emission and energy-effective reduction among the province based on cost of inputs and revenue of outputs.

Our empirical study concludes:

1) From a regional perspective, southern China has the most efficient score. Northern, eastern, and central China have similar performance, with efficiency scores all between 0.84 and 0.86 . Northeastern China has the worst performance (0.5287) among these areas. The efficiency scores of southeastern and northwestern China are little higher than for northeastern China, but there are also some provinces such as Shanxi, Chongqing, Guizhou, Shaanxi, and Gansu whose efficiencies are below 0.5. 8 provinces performed poorly with efficiency scores lower than 0.5 , but higher than before.

2) Price factor has a significant influence on energy use and on the $\mathrm{CO}_{2}$ emission efficiency scores of some provinces - especially Heibei, Shanxi, Shanhai, Henan, Guangxi, Yunnan, and Ningxia. The average of all DMU efficiency scores is higher than that in the SBM model, reflecting the energy use and that $\mathrm{CO}_{2}$ emission efficiency scores of 30 provinces actually are at a higher level when we consider the true price.

3) Northern and northeastern China should put more effort toward energy consumption reduction in order to improve efficiency scores. Instead, northeastern and central China should pay more attention to the improvement of energy conversion technology in order to increase their energy use and $\mathrm{CO}_{2}$ emission efficiency.

The following avenue is given for further research. First, we can analyze the efficiency score from different areas and different industries. Second, according to the government policy, research the appropriate interval of carbon tax. Calculate efficiency scores of different regions under the different carbon tax. Third, study the trend of efficiency score in a period of time.

\section{Acknowledgements}

This study is supported by the Social Science Foundation of Beijing (13JGB050).

\section{References}

1. SUEYOSHI T., GOTO M. DEA radial measurement for environmental assessment: a comparative study between Japanese chemical and pharmaceutical firms. Applied Energy, 115 (4), 502, 2014.

2. IPCC 2006, 2006 IPCC Guidelines for National Greenhouse Gas Inventories, Prepared by the National Greenhouse Gas Inventories Programme, Eggleston H.S., Buendia L., Miwa K., Ngara T. and Tanabe K. (eds). Published: IGES, Japan.

3. ZHANG C.Q., ZHANG M., ZHANG N. $\mathrm{CO}_{2}$ Emissions from the Power Industry in the China's Iteijing-Tianjin- 
Hebei Region: Decomposition and Policy Analysis. Polish journal of environmental studies, 26 (2), 903, 2017.

4. WANG K., WEI Y.M., ZHANG X. Energy and emissions efficiency patterns of Chinese regions: a multi-directional efficiency analysis. Applied Energy, 104 (2), 105, 2013.

5. ZENG S., XU Y., WANG L., CHEN J., LI Q. Forecasting the Allocative Efficiency of Carbon Emission Allowance Financial Assets in China at the Provincial Level in 2020. Energies, 9 (5), 329, 2016.

6. HRAFNKELSSON B., ODDSSON G.V., UNNTHORSSON R. A Method for Estimating Annual Energy Production Using Monte Carlo Wind Speed Simulation. Energies, 9 (4), 286, 2016.

7. LI W., ZHANG H.X. Decomposition Analysis of Energy Efficiency in China's Beijing-Tianjin-Hebei Region. Polish Journal of Environmental Studies, 26 (1), 189, 2017.

8. SUN J., WU J., LIANG L., ZHONG R.Y., HUANG G.Q. Allocation of emission permits using DEA: centralised and individual points of view. Int J Prod Res, 52 (2), 419, 2014.

9. WANG K., ZHANG X., WEI Y.M., YU S. Regional allocation of $\mathrm{CO}_{2}$ emissions allowance over provinces in China by 2020. Energy Policy, 54 (3), 214, 2013.

10. CHARNES A., COOPER W.W., RHODES E. Measuring the efficiency of decision making units. European Journal of Operational Research, 2 (6), 429, 1987.

11. KORHONEN P., SYRJÄNEN M. Resource allocation based on efficiency analysis. Manage Sci, 50 (8), 1134, 2004.

12. ZHOU Y., XING X., FANG K., LIANG D., XU C. Environmental efficiency analysis of power industry in China based on an entropy SBM model. Energy Policy, 57 (7), 68, 2013.

13. FLORENS F., DIRK R., STEFAN V. An analysis of the economic determinants of energy efficiency in the European iron and steel industry. Journal of Cleaner Production, 104, 250, 2015.

14. YUAN P., CHENG S. Determinants of Carbon Emissions Growth in China: A Structural Decomposition Analysis. Energy Procedia, 5 (1), 169, 2011.

15. SHENG P., YANG J., SHACKMAN J.D. Energy's Shadow Price and Energy Efficiency in China: A Non-Parametric Input Distance Function Analysis. Energies, 8 (3), 1975, 2015.

16. MING C., XIAOPING W. Chinese Industrial Energy Efficiency Evaluation Considering Carbon Emissions. International Conference on Computer Distributed Control \& Intelligent Environmental Monitoring: Changsha, China, 2011.

17. WANG S., CHU C., CHEN G., PENG Z., F LI. Efficiency and reduction cost of carbon emissions in China: A nonradial Directional Distance Function method. Journal of Cleaner Production, 113, 624, 2016.

18. YANG J., ZHANG T., SHEN P., SHACKMAN J.D. Carbon dioxide emissions and interregional economic convergence in China. Economic Modelling, 52, 672, 2016.

19. CHEN Z., YOU J., MA J. Inter-Provincial Difference and Causes Analysis of Total Factor $\mathrm{CO}_{2}$ Emissions
Performance in China. Asia-pacific Power \& Energy Engineering Conference: Wuhan, China, 2011.

20. ROIF F., SHAWNA G. Modeling undesirable factors in efficiency evaluation. European Journal of Operational Research, 157 (1), 242, 2004.

21. SUN W., S/HE Y.J., GAO H.S. An Electric Carbon Productivity Analysis of China's Industrial Sector Using Multi-Dimensional Decomposition. Polish journal of environmental studies, 25 (4), 1699, 2016.

22. FANG Z., HONG F., WU J.J., DAMIAN W. Environmental Efficiency Analysis of Listed Cement Enterprises in China. Sustainability, 8 (5), 453, 2016.

23. OGGIONI G., RICCARDI R., TONINELLI R. Ecoefficiency of the world cement industry: A data envelopment analysis. Energy Policy, 39 (5), 2842, 2011.

24. COOK W.D., GREEN R.H. Evaluating power plant efficiency: A hierarchical model. COMPUTERS \& OPERATIONS RESEARCH, 32 (4), 813, 2005.

25. BENYAMIN K., SHAHIN R., MAHMOUD O., HOSSEIN M. Cover image applying data envelopment analysis approach to improve energy efficiency and reduce GHG (greenhouse gas) emission of wheat production. Energy, $\mathbf{5 8}$ (1), 588, 2013.

26. MOUSAVI-AVVAL S.H., RAFIEE S., JAFARI A., MOHAMMADI A. Improving energy use efficiency of canola production using data envelopment analysis (DEA) approach. Energy, 36 (5), $2765,2011$.

27. CHAUHAN N.S., MOHAPATRA P.K.J., PANDEY K.P. Improving energy productivity in paddy production through benchmarking dan application of data envelopment analysis. Energy Conversion and Management, 47 (9-10), 1063, 2006.

28. FLÁVIA D.C.C., DAISY R., ROBERTA T.R. Energy efficiency analysis of BRICS countries: a study using Data Envelopment Analysis. Gest Prod, 23 (1), 192, 2016.

29. WANG Z.H., FENG C. The impact and economic cost of environmental regulation on energy utilization in China. Applied Economics, 46 (27), 3362, 2014.

30. BLANCARD S., MARTIN E. Energy efficiency measurement in agriculture with imprecise energy content information. Energy Policy, 66 (66), 198, 2014.

31. JUO J.C., FU T.T., YU M.M., LIN Y.H. Profit-oriented productivity change. Omega, 57, 176, 2015.

32. GOLANY B., ROLL Y. An application procedure for DEA. Omega, 17 (3), 237, 2009.

33. MENG M., NIU D.X. Modeling $\mathrm{CO}_{2}$ emissions from fossil fuel combustion using the logistic equation. Energy, 36 (5), 3355, 2011.

34. WANG K., ZHANG X., WEI Y.M., YU S. Regional allocation of $\mathrm{CO}_{2}$ emissions allowance over provinces in China by 2020. Energy Policy, 54 (3), 214, 2013.

35. WU J., ZHU Q., CHU J., LIU H., LIANG L. Measuring energy and environmental efficiency of transportation systems in China based on a parallel DEA approach. Transportation Research Part D: Transport and Environment, 48, 460, 2016. 
